\title{
Clinical Application of the Polymerase Chain Reaction for a Rapid Diagnosis of Mycobacterium tuberculosis Infection
}

\author{
Yoshimi KIKUchI, Shinichi OKa, Satoshi Kimura, Keiji Mitamura and Kaoru Shimada
}

\begin{abstract}
A gene amplification method of Mycobacterium tuberculosis DNA by the polymerase chain reaction (PCR) has been devised. A primer pair used in this study is 5'GTTGCCGTGGCGG TATCGG3' and 5'GCGACATTACGGGGCAGGTGG3', which brackets a 152-base region encoding the 65KD antigen, and a specific probe is 5'TTTGGGGTCATCTTTGGAGCG3'. The procedure could be completed within 2 days. The specificity and the sensitivity of the PCR for $M$. tuberculosis complex in identifying $M$. tuberculosis complex did not conflict with the conventional methods at all. Using this method, we could diagnose three cases of the disease, which had been very difficult to diagnose by the conventional methods, by detecting the DNA from the blood, liver biopsy specimen, lung aspirate, and pleural effusion.
\end{abstract}

(Internal Medicine 31: 1016-1022, 1992)

Key words: gene amplification, $65 \mathrm{KD}$ antigen, $M$. tuberculosis complex, laboratory diagnosis, clinical use

\section{Introduction}

Tuberculosis is still prevalent in the world $(1,2)$. For the definitive diagnosis of tuberculosis, Mycobacterium tuberculosis (M. tuberculosis) has to be isolated and identified from clinical specimens. However, it takes up to 6 to 8 weeks to recover the mycobacteria by the conventional methods (3). Therefore, when the organism can not be identified directly by the acid-fast stains, a tentative diagnosis has to be made by radiographic examinations and clinical symptoms including non-specific symptoms, such as fever, general fatigue, weight loss, and lymphadenopathies. Furthermore, in some cases in which tuberculosis is strongly suspected clinically, anti-tuberculosis drugs are started to confirm clinical diagnosis. However, under immunosuppressed conditions (4) caused by steroid and/or immunosuppressive drugs or in patients with acquired immunodeficiency syndrome (AIDS) $(5,6)$, it is very difficult to make the clinical diagnosis because of atypical clinical features in comparison with those of lung tuberculosis in non-compromised hosts.

There are several methods to identify acid-fast bacteria. A microscopic examination of a smear by Ziehl-Neelsen staining is the most rapid and cheap method for detection of mycobacteria. However, this method can not detect mycobacteria when there are $10^{4} / \mathrm{ml}$ or less of the mycobacterial population in the smear (7), and it can not distinguish $M$. tuberculosis from other mycobacteria. DNA probes for $M$. tuberculosis have been developed and some of them are now commercially available (8). Although they can discriminate $M$. tuberculosis and other mycobacteria, the detection limit of the method is $10^{7} / \mathrm{ml}(8)$. Therefore, it is used to identify the colonies on agar after culture of clinical materials for 4 to 8 weeks. The radiometric system (BACTEC $^{\mathrm{TM}}$; Johnston Laboratories, Inc., Towson, MD, USA) (9) has greatly reduced the time for detection, but a culture for 10 to 12 days is still necessary. Consequently, a culture of clinical materials is indispensable in both methods. Accordingly, rapid, sensitive, and specific methods for detection of $M$. tuberculosis have long been desired and are more important in recent clinical situations.

In fact, we had experienced an AIDS patient with disseminated tuberculosis (6). This case was very atypical regarding disseminated tuberculosis, and rather resembled malignant lymphoma. This case and others had prompted us to develop a new rapid diagnostic method of $M$. tuberculosis, DNA amplification by the polymerase chain reaction (PCR). The method has already been applied for the detection of mycobacterial DNA such as the genes encoding $65 \mathrm{KD}$ antigen $(10,11)$, MPB64 protein $(12,13)$, antigen b (14), repetitive sequences (15-19), pMTb4 (20) and ribosomal RNA (21) as well as a number of other infectious

From the Department of Infectious Diseases, Institute of Medical Science, University of Tokyo, Tokyo

Received for publication September 2, 1991; Accepted for publication June 3, 1992

Reprint requests should be addressed to Dr. Yoshimi Kikuchi, the Department of Infectious Diseases, Institute of Medical Science, University of Tokyo, 4-6-1, Shiroganedai, Minato-ku, Tokyo 108, Japan 
agents (22-24). These previous reports mainly focused on basic investigations, and few have been directly applied for clinical specimens (19). Because it is difficult to recover a very small amount of $M$. tuberculosis DNA from clinical specimens, we modified the step of sample preparation, and used HLA-DQ $\alpha$ gene amplification (25) as an internal control.

In this report, we discuss three cases of tuberculosis, which had been very difficult to diagnose by the conventional methods, but were diagnosed by PCR. Furthermore, in one case, $M$. tuberculosis DNA shedding in blood was monitored by PCR, indicating the potential use of PCR as a therapeutic marker of the disease.

\section{Materials and Methods}

\section{Strains of mycobacteria}

The reference strains of mycobacteria examined for the specificity and sensitivity of a primer pair for $M$. tuberculosis were as follows; three strains of $M$. tuberculosis complex standards (M. tuberculosis NIHJ 1633, M. bovis NIHJ 1607, $M$. africanum NIHJ 1602), two strains of $M$. avium-M. intracellulare complex (MAC) standards ( $M$. avium NIAH 1106, $M$. intracellulare NIHJ 1618), seven strains of atypical mycobacteria other than MAC (nonMAC) (M. kansasii NIHJ 1619, M. scrofulaceum NIHJ 1626, $M$. gordonae NIHJ 1627, $M$. xenopi NIHJ 1638, $M$. gastri NIHJ 1616, $M$. fortuitum NIHJ 1615, M. chelonei NIHJ 1611). Seventeen clinical isolates of $M$. tuberculosis, which were identified by the conventional tests including growth rate, colony shape, pigmentation, and tests for niacin, catalase, nitrate reduction, and urease, obtained from the University of Tokyo Hospital, were tested for the sensitivity. To examine the detection limit, $M$. tuberculosis (NIHJ 1633) grown on Ogawa slant agar was suspended in double distilled water (DDW) and adjusted to $10^{3}$ cells $/ \mathrm{ml}$. The suspension was then serially diluted from $10^{3}$ cells $/ \mathrm{ml}$ to one cell $/ \mathrm{ml}$. Each diluted sample was again cultured to confirm the number of the cells contained.

\section{DNA extraction from reference strains of mycobacteria}

The mycobacterial suspensions $\left(10^{3}\right.$ cells $\left./ \mathrm{ml}\right)$ prepared from the reference strains were centrifuged for 15 minutes at $15,000 \times \mathrm{g}$. The pellets were resuspended in $250 \mu \mathrm{l}$ of lysate buffer $(25 \%$ sucrose, $50 \mathrm{mM}$ Tris- $\mathrm{HCl}, 50 \mathrm{mM}$ EDTA, pH 8.0 , lysozyme $1 \mathrm{mg} / \mathrm{ml}$ ) and incubated for 90 minutes at $37^{\circ} \mathrm{C}$. Twenty $\mu$ l of proteinase $\mathrm{K}(\mathrm{PK})$ at a final concentration of $200 \mu \mathrm{g} / \mathrm{ml}$, and $20 \mathrm{mg} / \mathrm{ml}$ of glycogen were added to the lysate and incubated for 15 minutes at $56^{\circ} \mathrm{C}$. Two hundred and fifty $\mu$ l of sodium dodecyl sulfate (SDS) at a final concentration of $5 \%$ was added to the lysate, and incubated for 15 minutes at $56^{\circ} \mathrm{C}$. The lysate was further incubated for 15 minutes at $95^{\circ} \mathrm{C}$ to inactivate PK. DNA was extracted with phenol/chloroform, and precipitated with ethanol (26), and resuspended in $500 \mathrm{ml}$ of TE [10 $\mathrm{mM}$ Tris- $\mathrm{HCl}(\mathrm{pH} 8.0)$ and $1 \mathrm{mM}$ EDTA $(\mathrm{pH} \mathrm{8.0)].}$

\section{DNA extraction from clinical specimens}

Clinical samples examined included blood, lung aspirate, pleural effusion, and liver biopsy specimens. All specimens were examined on acid-fast stained smear and cultured on Ogawa slant agar. To extract the DNA from the blood, 1 $\mathrm{ml}$ of $6 \%$ dextran and $2 \mathrm{ml}$ of heparinized blood were mixed and kept at room temperature for 30 minutes. The supernatant was centrifuged for 15 minutes at $15,000 \times \mathrm{g}$. After washing the pellet twice with DDW to remove dextran, and to lyse the red blood cells, the pellet was treated in the same manner as reference strains. The lung aspirate or pleural effusion was centrifuged and washed twice with DDW to lyse the contaminated red blood cells. After centrifugation, the pellet was treated in the same manner as described above. For the liver biopsy specimen, the tissue was pulverized in liquid nitrogen. Tissue powder was treated in the same manner as reference strains.

\section{A primer pair and a probe of the PCR assay}

A pair of 19- and 21-base oligonucleotides which brackets a 152-base region of a gene encoding 65-KD antigen (27) was selected and synthesized. The sequences of the primer pair were (from the 5' to the 3' ends) GTTGCCGTGGC GGTATCGG and GCGACATTACGGGGCAGGTGG. A corresponding oligonucleotide probe (from the 5' to the 3' ends; TTTGGGGTCATCTTTGGAGCG) was used to confirm the amplified product and to increase the detective sensitivity of the assay in clinical specimens. The probe was labeled with $\left[\gamma-{ }^{32} \mathrm{P}\right]$ ATP using T4 polynucleotide kinase (Takara) before use.

\section{DNA amplification}

A $50 \mu \mathrm{l}$ aliquot of DNA amplification reaction mixture containing $10 \mathrm{mM}$ Tris- $\mathrm{HCl}, 0.01 \%$ gelatin, $10 \mathrm{pM}$ each of the primer, $2 \mathrm{mM}$ dNTP, $2 \mathrm{U}$ of $T a q$ polymerase (Takara), and $50 \mu \mathrm{l}$ of specimen's DNA were mixed in a $500 \mu l$ tube, which was overlaid by $100 \mu l$ of heavy mineral oil. The mixture was amplified 40 cycles with denaturation at $95^{\circ} \mathrm{C}$ for 1 minute, annealing at $68^{\circ} \mathrm{C}$ for 2 minutes, and extension at $72^{\circ} \mathrm{C}$ for 1 minute. As an internal control, a primer pair and a probe obtained from HLA-DQ $\alpha$ gene (25) with the respective following sequences (from the 5 ' to the 3' ends) were used; GTGCTGCAGGTGTAAACTTG TACCAG and CACGGATCCGGTAGCAGCGGTAGAG TTG, and CTACGTGGACCTGGAGAGGAAGGAG ACTGCCTG.

In the reference strains and clinical isolates, the amplified product was subjected to a $3 \%$ agarose gel electrophoresis and visualized by staining with ethidium bromide $(0.5$ $\mu \mathrm{g} / \mathrm{mi})$ and photographed. In the clinical specimens, the product was hybridized with the ${ }^{32} \mathrm{P}$-labeled probe in liquid solution and subjected to a $8 \%$ polyacrylamide gel electrophoresis. The gel was exposed to Kodak X-O mat film at $-70^{\circ} \mathrm{C}$ for 6 to 12 hours. 


\section{Case Reports}

\section{Case 1}

A 37-year-old woman visited to our hospital on September 6, 1990, because of fever and general fatigue. She was well until 7 days earlier, when she experienced the sudden onset of a fever of $39^{\circ} \mathrm{C}$ without cough or rhinorrhea. At that time her private physician had administered antibiotics, but her temperature did not decrease. Physical examination on admission showed a temperature of $39.2^{\circ} \mathrm{C}$ and pulse of $104 / \mathrm{min}$. The bulbar conjunctiva were icteric and slightly anemic. The ocular fundi were normal. A couple of non-tender cervical lymph nodes, about $1 \mathrm{~cm}$ in diameter, were palpable. The lungs were clear on auscultation. The urine gave a positive test for protein, and was otherwise normal. The hemoglobin concentration was $12.0 \mathrm{~g} / \mathrm{dl}$, the white-cell count was $6,800 / \mu 1 \quad(87 \%$

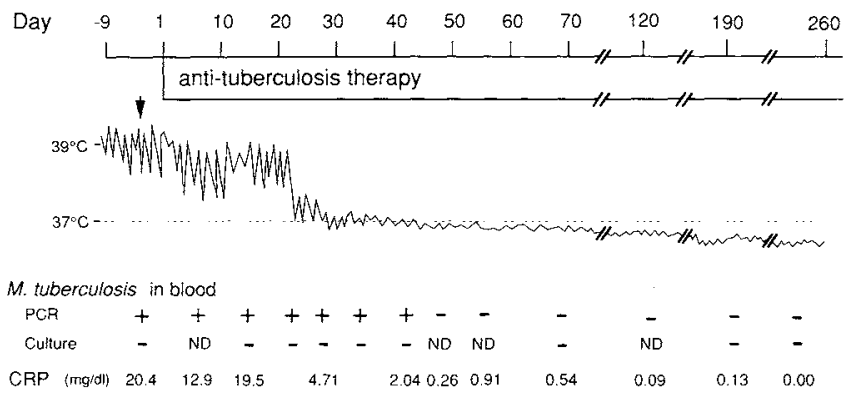

Fig. 1. Clinical course of a patient with miliary tuberculosis (case 1). Day one indicates September 15, 1990, when anti-tuberculosis therapy was started. The patient was admitted to the hospital on September 6, (day-9). The arrow indicates the time of liver biopsy (day-3). ND: not done.

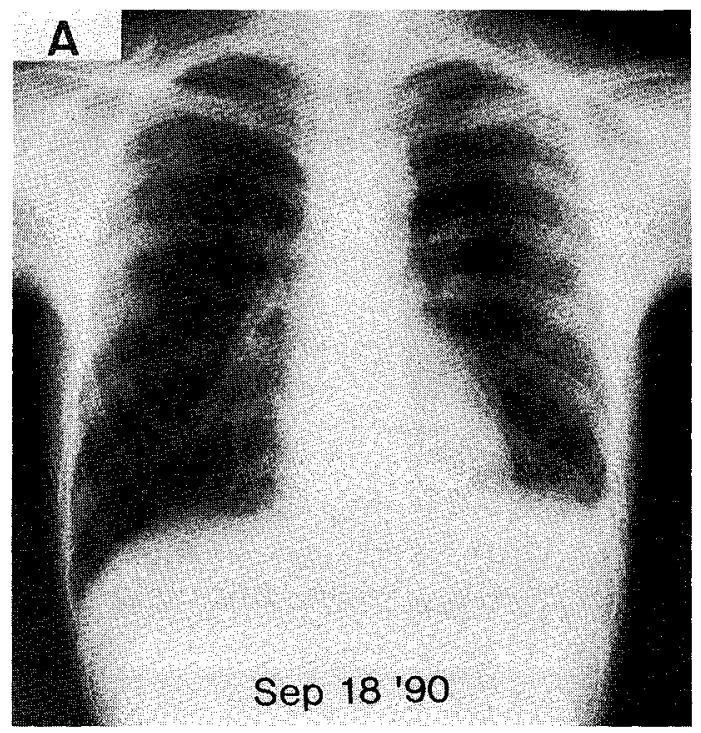

neutrophils, $8 \%$ lymphocytes, and 5\% monocytes), and platelet count was $87,000 / \mu \mathrm{l}$. Inflammatory parameters such as ESR (118 mm/hour) and CRP $(20.4 \mathrm{mg} / \mathrm{dl})$ were markedly elevated. Liver dysfunction was also noted; GOT $91 \mathrm{IU} / 1$ (normal <30), GPT $191 \mathrm{IU} / 1$ (normal <30), Alp $1,139 \mathrm{IU} / 1$ (70-290), and total bilirubin $3.1 \mathrm{mg} / \mathrm{dl}$ (conjugated bilirubin $2.5 \mathrm{mg} / \mathrm{dl}$ ). A skin test for tuberculosis by purified protein derivative (PPD) performed on September 12 was negative. Specimens of blood, urine, and feces obtained for culture of bacteria as well as mycobacteria were all repeatedly sterile. The liver biopsy done on September 12 revealed granuloma. However, the acid-fast stain and the culture of the specimen were negative. $M$. tuberculosis DNA was detected by PCR with the specific primer pair of $M$. tuberculosis from the liver biopsy specimen and blood obtained on September 14. Her clinical course is shown in Fig. 1. An anti-tuberculosis therapy consisting of $450 \mathrm{mg} /$ day of rifampicin (RFP), $500 \mathrm{mg} /$ day of isoniazid (INH), and $750 \mathrm{mg}$ /day of ethambutol (EB) was started from September 15. Fever came down to normal within one month and the PPD test became positive 3 months later. She was discharged from the hospital in June 1991.

\section{Case 2}

An 18-year-old hemophiliac was admitted to our hospital on September 13, 1990. He suffered from severe oral candidiasis 2 weeks before entry, and from the left-sided lateral chest pain one day before admission. Serological tests for human immunodeficiency virus type-1 (HIV-1) were positive. The white cell count was $6,800 / \mu 1$, the absolute CD4 + lymphocyte count $14 / \mathrm{ml}(800-1,600 / \mu 1)$, and CD4+/CD8 + lymphocyte ratio 0.03 (1.54-1.94). ESR was $83 \mathrm{~mm} /$ hour and CRP was $7.12 \mathrm{mg} / \mathrm{dl}$. The

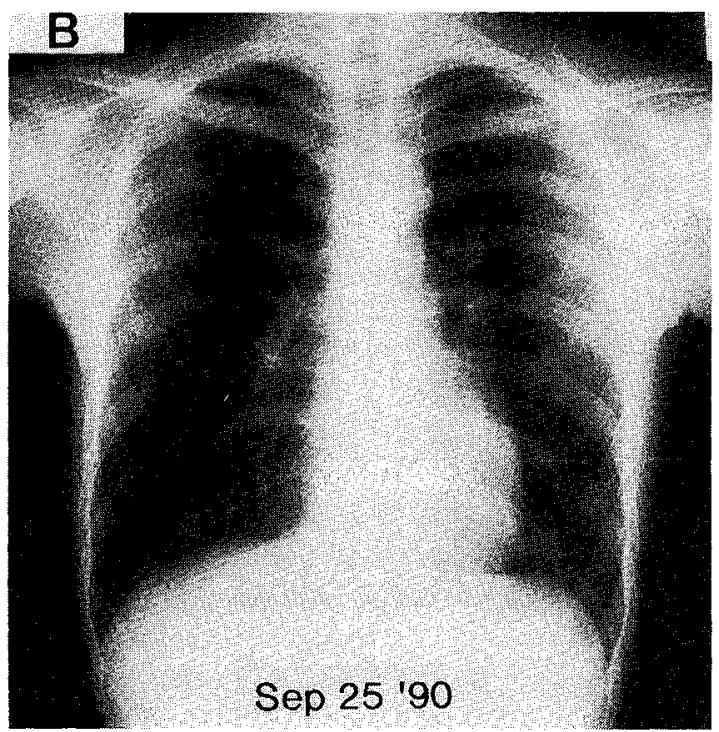

Fig. 2. Chest X-ray films of tuberculous pleurisy (case 2). Left-side pleural effusion was noted on September 18, 1990 (A), and disappeared by September 25 (B). 
PPD test was negative. The chest $\mathrm{X}$-ray revealed no abnormality on admission. However, left-sided pleural effusion appeared on September 18 (Fig. 2A). The blood gas measurement was within the normal limit. The puncture of the effusion was performed on September 21. $M$. tuberculosis DNA was detected from the specimen by PCR. However, the culture of the specimen was negative. An antituberculosis therapy (INH $500 \mathrm{mg}$, RFP $450 \mathrm{mg}$, and EB $1.0 \mathrm{~g}$ daily) was begun from September 24 . The chest X-ray reurned to normal on September 25 (Fig. 2B). The therapy has been continued and he remains well over the ensuing 11 months.

\section{Case 3}

A 22-year-old hemophiliac who had HIV-1 antibody, and had a history of Pneumocystis carinii pneumonia (PCP) (June 1989) was hospitalized from August 5 to September 5, 1989 because of the localized herpes zoster. The aspiration lung biopsy was carried out on August 15 as a PCP follow-up. The sample was examined for $M$. tuberculosis by the conventional methods, and a part of the sample was stored at $-40^{\circ} \mathrm{C}$. Although the PPD test was positive at that time, the sample was sterile on culture. One year later, he was readmitted to our hospital on July 9, 1990, with a one-week history of fever $\left(39^{\circ} \mathrm{C}\right)$ and productive cough with mucus sputa. On physical examination, no rales were audible over his chest. The chest X-ray revealed a faint increase of the peribronchial markings of both lungs. He had a white cell count of $3,100 / \mu 1$ and an absolute CD4+ lymphocyte count of $36 / \mu 1$. The blood gas measurement under room air revealed the partial pressure of the carbon dioxide of $37.5 \mathrm{mmHg}$ and the partial pressure of the oxygen of $79.7 \mathrm{mmHg}$. The acid-fast stain of sputa of a consecutive three-days were all negative, and culture of them were also negative. The aspiration lung biopsy was repeated on July 12 and the biopsy specimen was examined for $M$. tuberculosis by the conventional methods and by PCR. $M$. tuberculosis DNA was detected only by PCR, and an anti-

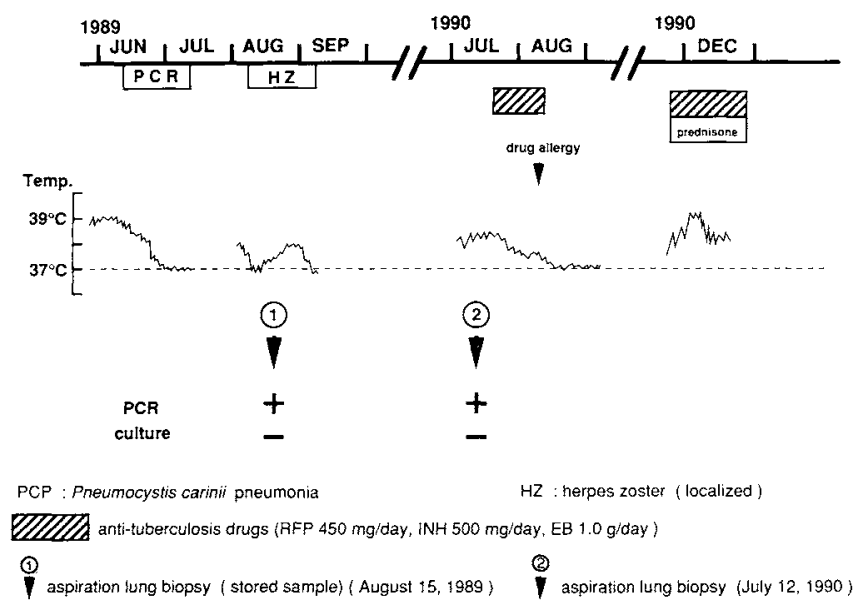

Fig. 3. Clinical course of a patient with lung tuberculosis (case 3). tuberculosis therapy (RFP, INH, and EB) was started on July 21 . However, as a drug allergy was noted, the therapy had to be discontinued on August 7. He had the final admission on November 26, 1990, with a one-month history of fever $\left(40^{\circ} \mathrm{C}\right)$ and the productive cough. Physical examination, the chest X-ray, and the laboratory data were almost the same as the last admission. Because tuberculosis was strongly suspected clinically and by the positive result of PCR of lung aspirate at the last admission, an antituberculosis therapy consisted of $450 \mathrm{mg} /$ day of RFP, 500 $\mathrm{mg} /$ day of INH, and $1.0 \mathrm{~g} /$ day of $\mathrm{EB}$ was initiated with $30 \mathrm{mg} /$ day of prednisone on November 28 . However, general conditions deteriorated and he died on December 26, 1990. An autopsy was performed and the disseminated cryptococcosis was identified. A cluster of M. tuberculosis was recognized in the subcarinal lymph nodes. His clinical course is represented in Fig. 3.

\section{Results}

Specificity, sensitivity, and the detection limit of $P C R$

All of the reference strains of $M$. tuberculosis, $M$. bovis, and $M$. africanum, namely $M$. tuberculosis complex, gave a 152-base signal by PCR with the primer pair (Fig. 4). In contrast, nine strains (two strains of MAC and seven strains of non-MAC) other than $M$. tuberculosis complex were not amplified. $M$. tuberculosis, $M$. bovis and $M$. africanum were not distinguished from one another. Human infection of $M$. bovis and $M$. africanum is generally not a clinical problem. All 17 clinical isolates known as $M$. tuberculosis defined by the conventional methods were also amplified (Fig. 5). Thus, the specificity and sensitivity of PCR for $M$.

\section{$M 123456789101112 \mathrm{~N}$}

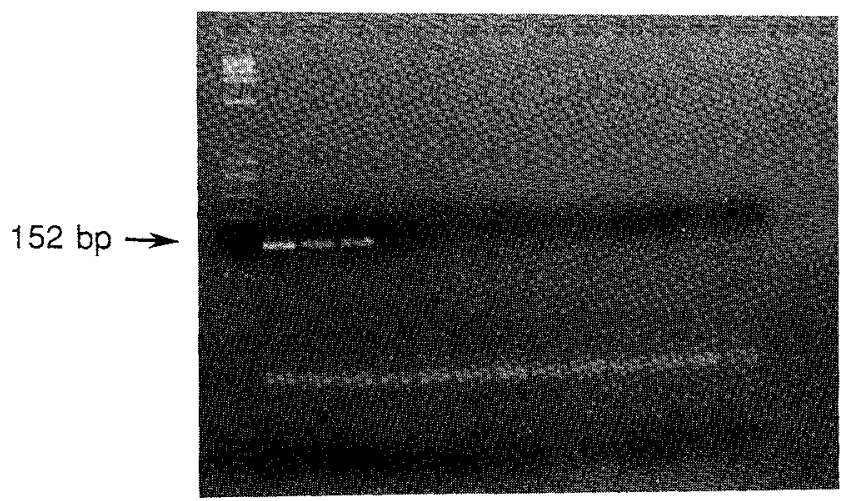

Fig. 4. The results of PCR for $M$. tuberculosis in the reference strains. A 152-bp gene fragment was amplified in $M$. tuberculosis complex standards. Lane M: Haelll-digested $\phi \times 174$ DNA, lane 1: $M$. tuberculosis NIHJ 1633, lane 2: $M$. bovis NIHJ 1607, lane 3: $M$. africanum NIHJ 1602, lane 4: $M$. avium NIAH 1106, lane 5: $M$. intracellulare NIHJ 1618, lane 6: $M$. kansasii NIHJ 1619, lane 7: $M$. scrofulaceum NIHJ 1626, Lane 8: $M$. gordonae NIHJ 1627, lane 9: $M$. xenopi NIHJ 1638, lane 10: $M$. gastri NIHJ 1616, lane 11: $M$. fortuitum NIHJ 1615, lane 12: $M$. chelonei NIHJ 1611, lane N: negative control. 
tuberculosis complex in identifying $M$. tuberculosis complex were consistent with the conventional methods. The examination of the detection limit by purified $M$. tuberculosis DNA revealed that the products from more than five
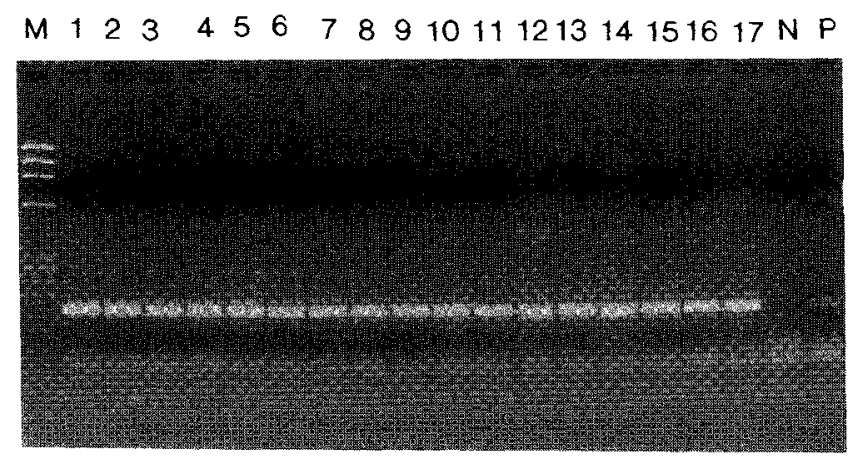

Fig. 5. The results of PCR for $M$. tuberculosis in known clinical isolates. All 17 clinical isolates of $M$. tuberculosis were amplified. Lane M: Haelli-digested $\phi \times 174$ DNA, lanes 1-17: clinical isolates, lane N: negative control, lane $\mathrm{P}$ : positive control.

HLA

\section{M. tuberculosis}

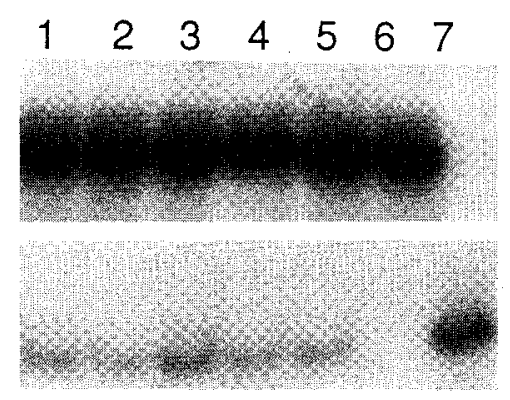

Fig. 6. Detection of $M$. tuberculosis DNA in clinical specimens by PCR. Lane 1: liver biopsy specimen from case 1 on September 12, 1990, lane 2: blood sample from case 1 on September 14, 1990, lane 3: pleural effusion from case 2 on September 21, 1990, lane 4: lung aspirate from case 3 on August 15, 1989 (stored sample), lane 5: lung aspirate from case 3 on July 12, 1990, lane 6: negative control (DNA obtained from human lymphocytes), lane 7: positive control ( $M$. tuberculosis NIHJ 1603). HLA indicates HLA-DQ $\alpha$ gene amplification by PCR as an internal control.

HLA

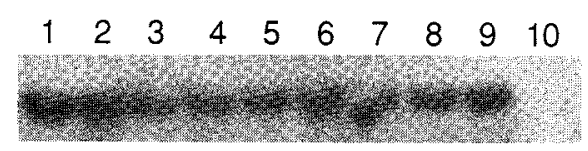

\section{M. tuberculosis}

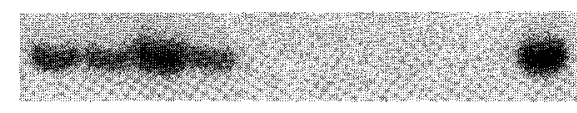

Fig. 7. Serial monitoring of $M$. tuberculosis DNA shedding in the blood by PCR (case 1). Lane 1: September 14, 1990, lane 2: September 28, lane 3: October 12, lane 4: October 26, lane 5: October 30, lane 6: November 21, lane 7: April 3, 1991, lane 8: June 7, 1991, lane 9: negative control (DNA obtained from human lymphocytes), lane 10: positive control (M. tuberculosis NIHJ 1603). HLA indicates HLA-DQ $\alpha$ gene amplification by PCR as an internal control. bacterial cells of $M$. tuberculosis were detected on an agarose gel by ethidium bromide staining (data not shown).

\section{Clinical applications of $P C R$}

Four types of clinical material (liver biopsy specimen of September 12, 1990 in case 1, the blood of September 14, 1990 in case 1, pleural effusion of September 21, 1990 in case 2, and lung aspirates of August 15, 1989 and of July 12,1990 in case 3 ) in the three patients presented here were positive by PCR for M. tuberculosis (Fig. 6). All of the rapid diagnosis of tuberculosis permitted us to initiate early treatment, with the exception of one lung aspirate of 1989 which was done retrospectively (case 3). Although none of the cultures of these specimens were positive, clinical improvement with anti-tuberculosis treatments in case 1 and case 2 were achieved, and $M$. tuberculosis was identified by autopsy in case 3 .

In case 1 , a total of 17 blood samples were tested during her hospitalization to follow up the clinical course (Fig. 1) by both the conventional methods and by PCR. All samples were negative by the culture. In contrast, seven consecutive samples obtained from September 14 through October 26 were positive by PCR for $M$. tuberculosis. After October 30 (on day 46 after the start of therapy), all blood samples turned to negative by PCR. Some of these results are shown in Fig. 7. In response to the anti-tuberculosis therapy, GOT and GPT returned to normal on day 15 , Alp and her temperature on day 25, CRP on day 47, and ESR on day 180. Therefore, comparing PCR results with the clinical course, they showed a good correlation with the improvement of CRP (Fig. 1).

\section{Discussion}

Our results showed that $M$. tuberculosis DNA can be amplified with high specificity, high sensitivity, and very low detection limit by PCR, and the method can be applied as a rapid laboratory diagnosis of tuberculosis. Several PCR assays for identifying $M$. tuberculosis DNA had already been reported using various primer pairs (10-21). In comparison with those reports, our method, which was independently developed, was consistent with those in basic investigations. However, in those reports, few demonstrated the clinical applications of their methods (19). In contrast, our method of sample preparation permitted detection of M. tuberculosis DNA directly in various clinical samples. Clearly, there are several difficulties in the clinical applications of PCR. First, the presence of proteins, lipids, sugars, and other substances contaminate the clinical materials and make it difficult to lyse the cell wall of mycobacteria. In our method, three steps of incubation with very high concentrations of sucrose $(25 \%)$, PK $(200 \mu \mathrm{g} / \mathrm{ml})$, and SDS $(5 \%)$ were used to lyse the cell wall efficiently and to extract M. tuberculosis DNA from various clinical samples. Second, non-specific DNA has an inhibitory effect on the detection limit of PCR. Therefore, we applied liquid hybridization 
of the amplified product and a radioisotopic probe to increase the sensitivity. However, to extend clinical applicability of this PCR method, further optimization of extraction and detective procedures will be needed to simplify the procedure and to improve the detection limit of the PCR method.

The three cases described in this report suggest PCR is useful as a rapid sensitive, and specific laboratory diagnostic tool of tuberculosis infections. All cases had been very difficult to diagnose by the conventional methods, because M. tuberculosis was not isolated from any of their clinical samples. Nevertheless, we could make the diagnosis of tuberculosis based on the PCR results, which were compatible with their clinical courses and the autopsy finding.

In case 1 , we could not only make a rapid diagnosis of miliary tuberculosis by PCR, but also follow up the clinical course. The monitoring of $M$. tuberculosis DNA in blood revealed that the bacteremia had persisted over 40 days in spite of an appropriate therapy. According to a good correlation of the persistence of the bacteremia with the duration of elevated levels of CRP, CRP may be one of the indispensable therapeutic markers which must be normalized before completing the treatment of miliary tuberculosis. This case suggests that PCR is useful not only for diagnosis but also for a marker in the monitoring of the course.

Case 2 was in a profound immunodeficient condition caused by HIV-1 infection. His clinical course of the tuberculous pleurisy was a rather atypical course. Only transient pleural effusion was noted, and there was no primary complex or pleural thickening on chest X-ray (Fig. 2A and 2B). If anti-tuberculosis therapy had not been administered, he might have a disseminated tuberculosis. A life-threatening disease was prevented by the rapid diagnosis by PCR.

In case 3, there were some complicated situations behind his history. First, he had had PCP which causes respiratory problems. The retrospective amplification of the stored lung aspirate was positive for $M$. tuberculosis by PCR (Fig. 6; lane 4). He had had a drug allergy to some anti-tuberculosis drugs and that forced us to use glucocorticoid in combination with the anti-tuberculosis therapy. Finally, he had had the disseminated cryptococcosis which was probably worsened by steroid. Although the significance of the retrospective result of the positive PCR is unclear, it is important to be aware of possible recurrence of primary tuberculosis in AIDS patients. Because of drug reactions, we could not continue the anti-tuberculosis therapy in August 1990, in spite of positive $M$. tuberculosis DNA in the lung aspirate detected by PCR (Fig. 6; lane 5). A retrospective examination of cryptococcal antigen in the serum revealed that the infection had occurred only after November 1990 . From the result, although $M$. tuberculosis was found at autopsy to exist only in the subcarinal lymph nodes, it might be that the respiratory symptoms starting in July 1990, were caused by lung tuberculosis.

In conclusion, a method for gene amplification of $M$. tuberculosis DNA by PCR was developed, and it is sensitive and specific enough for clinical use. While further investigations are still needed, it is a powerful and a reliable laboratory tool for a rapid diagnosis of tuberculosis.

Acknowledgements: We are grateful to Ms. K. Okuzumi for providing type strains of mycobacteria and clinical isolates of $M$. tuberculosis, and to Ms. M. Goto for her excellent technical assistance.

This work was supported in part by grants from the Ministry of Health and Welfare of Japan, and from the Ministry of Education, Science and Culture of Japan.

\section{References}

1) Rieder HL, Cauthen GM, Kelly GD, Bloch AD, Snider DE Jr. Tuberculosis in the United States. JAMA 262: 385, 1989.

2) Styblo K. Overview and epidemiologic assessment of the current global tuberculosis situation with an emphasis on control in developing countries. Rev Infect Dis 11 (Suppl) 2: S339, 1989.

3) Bates JH. Diagnosis of tuberculosis. Chest (Suppl) 76: 757, 1979.

4) Higgins RM, Cahn AP, Porter D, et al. Mycobacterial infections after renal transplantation. Q J Med 78: 145, 1991.

5) Barnes PF, Bloch AD, Davidson PT, Snider DE Jr. Tuberculosis in patients with human immunodeficiency virus infection. J Engl J Med 324: 1644, 1991.

6) Kikuchi $Y$, Oka S, Goto M, et al. A case of human immunodeficiency virus infection related Mycobacterium tuberculosis with atypical clinical features. J Jpn Assoc Infect Dis 65: 888, 1991 (in Japanese).

7) Yeager H Jr, Lacy J, Smith LR, LeMaistre CA. Quantitative studies of mycobacterial populations in sputum and saliva. Am Rev Respir Dis 95: 998, 1967.

8) Gonzalez R, Hanna BA. Evaluation of Gen-Probe DNA hybridization systems for the identification of Mycobacterium tuberculosis and Mycobacterium avium-intracellulare. Diagn Microbiol Infect Dis 8: 69, 1987.

9) Roberts GD, Goodman NL, Heifets L, et al. Evaluation of the BACTEC radiometric method for recovery of mycobacteria and drug susceptibility testing of Mycobacterium tuberculosis from acid-fast smear-positive specimens. J Clin Microbiol 27: 241, 1989.

10) Hance AJ, Grandchamp B, Lévy-Frébault V, et al. Detection and identification of mycobacteria by amplification of mycobacterial DNA. Molec Microbiol 3: 843, 1989.

11) Pao CC, Yen TS, You JB, Maa JS, Fiss EH, Chang CH. Detection and identification of Mycobacterium tuberculosis by DNA amplification. J Clin Microbiol 28: 1877, 1990.

12) Shankar $P$, Majunath $N$, Lakshmi R, Aditi B, Seth $P$, Shriviwas. Identification of Mycobacterium tuberculosis by polymerase chain reaction. Lancet i: $423,1990$.

13) Manjunath N, Shankar P, Rogan L, Bhargava A, Saluja S, Shirinwas. Evaluation of the polymerase chain reaction for a diagnosis of tuberculosis. Tubercule 72: 21, 1991.

14) Sjöbring $U$, Mecklenburg $M$, Andersen $A B$, Miörner H. Polymerase chain reaction for detection of Mycobacterium tuberculosis. J Clin Microbiol 28: 2200, 1990.

15) Eisenach KD, Cave MD, Bates JH, Crawford JT. Polymerase chain reaction amplification of a repetitive DNA sequence specific for Mycobacterium tuberculosis. J Infect Dis 161: 977, 1990.

16) Hermans PWM, Schuitema ARJ, Van Soolingen D, et al. Specific detection of Mycobacterium tuberculosis complex strains by polymerase chain reaction. J Clin Microbiol 28: 1204, 1990.

17) De Wit D, Steyn L, Shoemaker S, Sogin M. Direct detection of Mycobacterium tuberculosis in clinical specimens by DNA amplification. J Clin Microbiol 28: 2437, 1990. 


\section{Kikuchi et al}

18) Thierry D, Brisson-Noël A, Vincent-Lévy-Frébault V, Nguyen S, Guesdon J, Gicquel B. Characterization of Mycobacterium tuberculosis insertion sequence, IS 6110 , and its application in diagnosis. J Clin Microbiol 28: 2668, 1990.

19) Brisson-Noel A, Aznar C, Chureau C, et al. Diagnosis of tuberculosis by DNA amplification in clinical practice evaluation. Lancet ii: $364,1991$.

20) Patel RJ, Fries JWU, Piessens WF, Wirth DF. Sequence analysis and amplification by polymerase chain reaction of a cloned DNA fragment for identification of Mycobacterium tuberculosis. J Clin Microbiol 28: 513, 1990

21) Böddinghaus B, Rogall T, Flohr T, Blöcker H, Böttger EC. Detection and identification of mycobacteria by amplification of rRNA. J Clin Microbiol 28: 1751, 1990.

22) Ou CY, Kwok S, Mitchell SW, et al. DNA amplification for direct detection of HIV-1 in DNA of peripheral blood mononuclear cells.
Science 239: 295, 1988.

23) Shibata D, Martin WJ, Appleman MD, et al. Detection of cytomegalovirus DNA in peripheral blood of patients infected with human immunodeficiency virus. J Infect Dis 1185: 158, 1988.

24) Kitada K, Oka S, Kimura S, et al. Detection of Pneumocystis carinii sequences by polymerase chain reaction: animal models and clinical application to noninvasive specimens. J Clin Microbiol 29: 1985, 1991.

25) Saiki RK, Bugawan TL, Horn GT, Mullis KB, Erlich HA. Analysis of enzymatically amplified b-globin and HLA-DO $\alpha$ DNA with allelespecific oligonucleotide probes. Nature 324: 163, 1986.

26) Sambrook J, Fritsch EF, Maniatis T. Molecular cloning, a laboratory manual, second edition. New York, USA. Cold Spring Harbor Press, 1989.

27) Shinnick TM. The 65-kilodalton antigen of Mycobacterium tuberculosis. J Bacteriol 169: 1080, 1987. 